\title{
Resistance training for activity limitations in older adults with skeletal muscle function deficits: a systematic review
}

This article was published in the following Dove Press journal:

Clinical Interventions in Aging

13 June 2017

Number of times this article has been viewed

\author{
Evan V Papa' \\ Xiaoyang Dong ${ }^{2}$ \\ Mahdi Hassan' \\ 'Department of Physical Therapy, \\ University of North Texas Health \\ Science Center, Fort Worth, TX, \\ USA; ${ }^{2}$ Department of Rehabilitation \\ Medicine, The First Affiliated \\ Hospital of Nanchang University, \\ Nanchang, Jiangxi Province, People's \\ Republic of China
}

\begin{abstract}
Human aging results in a variety of changes to skeletal muscle. Sarcopenia is the age-associated loss of muscle mass and is one of the main contributors to musculoskeletal impairments in the elderly. Previous research has demonstrated that resistance training can attenuate skeletal muscle function deficits in older adults, however few articles have focused on the effects of resistance training on functional mobility. The purpose of this systematic review was to 1) present the current state of literature regarding the effects of resistance training on functional mobility outcomes for older adults with skeletal muscle function deficits and 2) provide clinicians with practical guidelines that can be used with seniors during resistance training, or to encourage exercise. We set forth evidence that resistance training can attenuate age-related changes in functional mobility, including improvements in gait speed, static and dynamic balance, and fall risk reduction. Older adults should be encouraged to participate in progressive resistance training activities, and should be admonished to move along a continuum of exercise from immobility, toward the recommended daily amounts of activity.
\end{abstract}

Keywords: aging, strength training, sarcopenia, mobility, balance

\section{Introduction}

Healthcare providers are anticipating a significant increase in the number of older adults living throughout the world. ${ }^{1}$ By 2030, the number of adults aged 65 or older in the US will more than double to approximately 71 million. ${ }^{2}$ As these individuals age, they will voluntarily decrease physical activity levels, which will result in a concomitant decline in muscle strength. ${ }^{3}$ Adequate muscular strength is fundamental to preserving functional mobility in older adults. Accordingly, the loss of muscle strength in elderly persons has been an increasingly important theme of research in recent years.

One of the leading factors associated with strength decline in older adults is the age-related reduction in muscle mass, known pathologically as sarcopenia. ${ }^{4,5}$ The term was originally described in a symposium in the 1960s by Dr Irwin H Rosenberg using the Greek words sarx and penia, signifying "loss of flesh". ${ }^{6}$ It was not until Rosenberg published his well-regarded manuscript in 1989 that the term became generally associated with age-related muscle loss. ${ }^{7}$

Since its 1989 recognition, the term sarcopenia has been embraced by various definitions due to improved understanding of the relationships between muscle mass, strength, and physical function. Seminal descriptions of sarcopenia were defined by the amount of muscle mass within a reference area. More recent evidence however suggests that community dwelling older adults experience weakness associated with low muscle
Correspondence: Evan V Papa Department of Physical Therapy, University of North Texas Health Science Center, 3500 Camp Bowie Blvd, MET 533, Fort Worth, TX 76107, USA Tel +l 8177357618 Email evan.papa@unthsc.edu 
mass and increased functional disability. For example, low physical function in older adults such as rising from a chair and performing personal care are directly associated with sarcopenia. ${ }^{8}$ Accordingly, more encompassing definitions of sarcopenia are now being adopted, such as skeletal muscle function deficits, which incorporate strength and physical function together with muscle mass.

There is strong evidence to suggest that skeletal muscle function deficits are treatable with exercise interventions. ${ }^{9}$ Specifically, resistance training (strength training exercise with progressive overload where muscles exert a force against an external load) is a safe and effective method of increasing strength in older adults. ${ }^{10,11}$ However, recent reports have suggested that improvements in physical disability and health related quality of life have been recalcitrant to resistance training. ${ }^{12}$ Moreover, the most expansive reviews on this topic are either outdated ${ }^{13}$ or have focused solely on the benefits of strength and power outcomes. ${ }^{14}$ When functional mobility outcomes are reported, they have been detailed in response to multi-modal exercise programs. ${ }^{15}$ As a result, researchers and clinicians are left to debate the impact of individual resistance training programs on physical function for older adults. Therefore, the purpose of this review was to isolate the effect of resistance training on physical function in older adults with skeletal muscle function deficits by updating the current literature via systematic review. We present evidence that resistance training results in improved functional mobility in older adults, including gait speed and gait kinematics, balance function, and limits of stability. We finish by providing clinicians with recommendations for resistance training interventions, which may attenuate age-related changes in muscle function.

\section{Methods}

This systematic review was conducted in accordance with the criteria outlined in the Preferred Reporting Items for Systematic Review and Meta-Analysis (PRISMA) statement. ${ }^{16}$

\section{Participants and study designs}

All resistance training interventions that included a primary or secondary outcome related to physical function were included in the original data acquisition. Study designs were included if they met the clinical trial definitions for levels I-IV evidence according to the Methodology to Develop Systematic Reviews of Treatment Interventions developed by the American Academy for Cerebral Palsy and Developmental Medicine (AACPDM) (2008 version, revision 1.2$).{ }^{17,18}$ Older adults living at home in the community or resident in institutions were included. Trials included participants with a mean age 60 or over from a variety of health conditions ranging from fit to frail. Studies were excluded if they included persons with neurological conditions such as stroke, multiple sclerosis, or Parkinson's disease.

\section{Types of interventions and outcome measures}

All trials that had a group of participants performing resistance training as the primary intervention were included in the original data acquisition. Resistance training was defined as any strength training program in which participants exercised a muscle against an external force that was set at specific intensity for each participant. ${ }^{19}$ Studies that included aerobic exercise, balance or other training measures were excluded. The primary outcome of this review was physical function. The outcomes were classified according to the Activity taxonomy from the International Classification of Functioning, Disability, and Health (ICF). ${ }^{20}$ In the context of the ICF model, the World Health Organization defines "Activity" as the execution of a task or action by an individual and "Activity limitations" as the difficulties an individual may have in executing activities. We operationally employed outcomes of interest reflecting balance and gait performance during activities of everyday living.

\section{Search strategy}

In accordance with the newest standards for updating systematic reviews, ${ }^{21}$ we have chosen to include only articles that were published after May 1, 2008, in order to provide new evidence based on need and priority. Our goal was to include studies from international journals published in the English language through November 2016. We conducted an extensive search using the following databases: PubMed, CINAHL, SPORTDiscus, PEDro (the Physiotherapy Evidence Database), and AgeLine. The subject specific search strategy was employed in PubMed based on previous reviews ${ }^{12,22}$ and modified for use in other databases. A flow diagram is included demonstrating the process of the search strategy according to the PRISMA flow sheet guidelines (Figure 1).

\section{Study selection}

Two authors independently reviewed the search results and extracted the data for full review. The data extraction forms included general study characteristics (groups, sample data, outcome measures), study information (authors, manuscript title, journal, publication year) and results. 


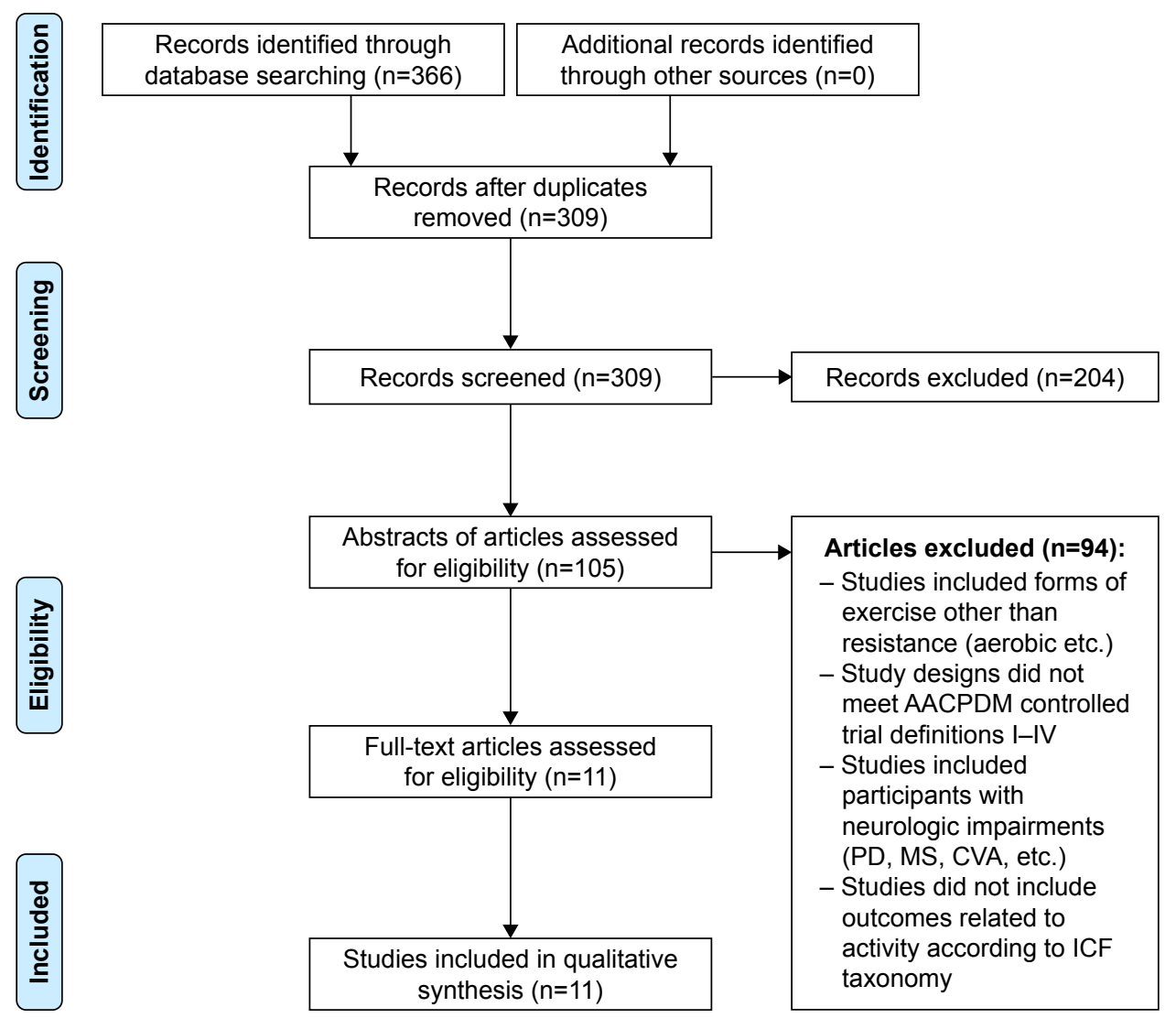

Figure I Literature search strategy, according to the Preferred Reporting Items for Systematic Reviews and Meta-Analyses guidelines.

Abbreviations: AACPDM, American Academy for Cerebral Palsy and Developmental Medicine; ICF, International Classification of Functioning; PD, Parkinson's disease; MS, multiple sclerosis; CVA, cerebrovascular accident.

Quality assessments of each study were performed using the AACPDM guidelines. If discrepancies were found during data extraction or regarding study quality they were resolved by referencing the original article and discussion between the two researchers. If the two authors could not reach a consensus agreement, the primary author became the arbiter and made the conclusive decision.

The AACPDM tool quantifies study quality by awarding one point for each of the following internal and external validity study characteristics: 1) inclusion and exclusion criteria were well-described and followed, 2) intervention was adequately described and followed, 3) outcome measures used were valid and reliable, 4) outcome assessor was unaware of the intervention status of participants (blinded), 5) authors conducted appropriate statistical tests including power analysis, 6) dropouts were reported and were less than $20 \%$, and 7) appropriate methods for controlling confounding variables and limiting potential biases were used. A score of 6 or greater was considered to reflect a high-quality trial, a score of 4 or 5 was considered to be moderate quality, and a score of 3 or less was considered to be low quality.

\section{Results General aspects}

A total of 366 citations were found, with 210 from PubMed, 84 from SPORTDiscus, 32 from CINAHL, 30 from PEDro and 10 from AgeLine. Articles were reviewed for duplicates, with 57 being removed and 309 studies remaining. Article titles were reviewed for evidence of resistance training interventions with functional mobility outcomes in older adults; those not exhibiting such characteristics were excluded ( $n=204)$. The abstracts of 105 articles were then reviewed in reference to our exclusion criteria, leaving a total of 11 articles for full text review (Figure 1).

\section{Study design and quality}

All 11 articles were prospective studies involving healthy older adults. Eight of the 11 studies were randomizedcontrolled trials, classified as level II on the AACPDM level of evidence scale. ${ }^{23-30}$ The remaining three articles did not have an active control group and were therefore, classified as level IV evidence. ${ }^{31-33}$ Four of the 11 articles were assessed a strong study quality rating, ${ }^{25,28,29,33}$ six were considered 
moderate quality,,$^{23,24,26,27,30,32}$ and one article was considered to provide weak individual study quality. ${ }^{31}$

\section{Study samples}

All older participants were considered healthy, communitydwelling adults with a mean age of 71.7 years (mean range 61.1-91.3 years). One study employed only male subjects, ${ }^{24}$ three utilized solely female participants, ${ }^{28,30,31}$ and the remaining seven reports included both sexes. . $3,25-27,29,32,33^{-33}$

\section{Exercise protocols}

Five studies focused on training the large muscle groups in the lower extremities..$^{24,28,30,32,33}$ Four of the studies examined the effects of full body resistance training. 23,27,29,31 Two studies focused on resistance training for the muscles in the core of the body including abdominals and spine stabilizers. ${ }^{25,26}$

There was a wide degree of heterogeneity between resistance training designs. Specific details of each training program can be seen in Table 1. The general consensus between the 11 articles was to use 1-hour training sessions on alternate days of the week, 2-3 times per week. Most of the studies also included a 2-minute rest break between sets. These studies also included a 10-minute aerobic warm up prior to the resistance training portion. All exercise sessions were supervised by a physical therapist, certified athletic trainer or other trained exercise science specialist.

\section{Functional outcomes}

All outcome measures focused on improvements in functional mobility of older adults. The most common outcomes included the Timed Up and Go test (TUG) ${ }^{25,28,29,31,33}$ and Functional Reach test (FR). ${ }^{24-26,33}$ The TUG is a dynamic test designed to assess mobility, balance, walking ability, and fall risk in older adults. The FR is a simple balance task that tests the ability of a person to move their center of mass to the anterior limits of their base of support by measuring the distance a participant can reach forward from a quiet stance position. Both outcomes have been validated as fall risk predictors in older adults. ${ }^{34-36}$ Full details of functional mobility outcomes can be seen in Table 1. Common secondary outcomes reported were strength gains, ${ }^{24,25,27,29,30,32}$ generic balance assessments, ${ }^{23,26,27,29,32,33}$ and measurements of gait speed $^{25,29,31}$ or gait kinematics. ${ }^{30}$

The article with the greatest overall effect sizes in functional measures examined forward (Cohen's $d$ 3.80) and backward (Cohen's $d$ 4.20) tandem walk test and FR test (Cohen's $d$ 5.28). ${ }^{24}$ This study implemented exercise for 60 minutes, 3 days per week, for 13 weeks. Participants performed exercise targeted at their individual 80\% 1 repetition maximum (RM), recalculated each week. The goal of this study was to strengthen the bilateral lower extremities and also included a 10 minute aerobic warm up and a 10 minute post resistance training cool down on the stationary bike.

\section{Discussion}

\section{Resistance training for older adults}

Muscle mass decreases approximately $2 \%$ every year after the age of $50 .{ }^{37}$ In a similar manner, there is an approximate $15 \%$ decrease in muscle strength every 10 years after the age of $50 .{ }^{38}$ However, resistance training can mitigate the loss of muscle mass and muscle strength. ${ }^{14}$ In order to attenuate the effects of sarcopenia, it has been recommended that older adults perform resistance training 2-3 days per week. ${ }^{39}$ Resistance training though, offers numerous benefits beyond improvements in muscle strength alone for older individuals. The purpose of this systematic review was to demonstrate the effects of resistance training on functional mobility outcomes as reported in papers published after May 1, 2008. Our findings corroborate and strengthen earlier reports, which also demonstrate improvements in balance, functional mobility and fall prevention. ${ }^{12}$ Articles with the most robust study design and strong study quality demonstrated improvements in Activity limitations following resistance training. Lustosa et al, and Granacher et al, demonstrated improved capacity to rise out of a chair, ambulate and make turns (TUG test), ${ }^{25,28}$ while Nicholson et al demonstrated improved gait speed and some aspects of standing balance. ${ }^{29}$ Articles with equally well-controlled designs, but moderate study quality also demonstrated functional improvements. Persch et al, found that resistance training was effective in reversing age-related changes in gait speed, toe clearance, and cadence. ${ }^{30}$ Static and dynamic balance were improved following 6 weeks ${ }^{23,26}$ and 13 weeks ${ }^{24}$ of resistance training, but no improvements in compensatory balance responses were reported. ${ }^{24}$ These results reinforce the premise that resistance training can play a fundamental role in improving functional mobility and activities of daily living for older adults. Additional research is needed however on the effects of resistance training and other substantive outcomes such as health related quality of life. ${ }^{12}$

\section{Recommendations for clinical practice}

Due to the abundant improvements in skeletal muscle function deficits with resistance training, this modality has been widely accepted as a leading clinical intervention for 
Table I Characteristics of included studies

\begin{tabular}{|c|c|c|c|}
\hline Study & $\begin{array}{l}\text { Population } \\
\text { (age } \pm \text { SD) }\end{array}$ & Intervention characteristics & Functional outcomes \\
\hline Gonzalez et al ${ }^{23}$ & $\begin{array}{l}M \& F \\
7 I . I \pm 6 . I\end{array}$ & $\begin{array}{l}2 \text { days/week for } 6 \text { weeks.* Dynamic warm-up. Full-body } \\
\text { progressive resistance training (RT) with three sets } \\
\text { of } 8-15 \text { repetitions. Intensity based on OMNI scale of } \\
\text { perceived exertion }\end{array}$ & Single Leg Balance (SLB) $d=0.47$ \\
\hline Granacher et $\mathrm{a}^{24}$ & $\begin{array}{l}M \\
67.0 \pm 1.0\end{array}$ & $\begin{array}{l}\text { I-hour session, } 3 \text { days/week for I } 3 \text { weeks. I0-minute } \\
\text { warm-up and cool-down on bike. Bilateral lower } \\
\text { extremity (BLE) regimen of four exercises with three sets } \\
\text { of } 10 \text { repetitions; } 2 \text {-minute rest between sets. RT load set } \\
\text { at } 80 \% \text { of I repetition maximum (I RM), adjusted weekly }\end{array}$ & $\begin{array}{l}\text { Functional Reach }(F R) d=5.28 \\
\text { Tandem Walk Test } \\
\text { Forwards } d=3.80 \\
\text { Backwards } d=4.20\end{array}$ \\
\hline Granacher et a ${ }^{25}$ & $\begin{array}{l}M \& F \\
70.8 \pm 4.1\end{array}$ & $\begin{array}{l}\text { I-hour session, } 2 \text { days/week for } 9 \text { weeks. Progressive RT } \\
\text { for frontal, dorsal, rotational, and lateral core muscles } \\
\text { with 3-4 sets of I } 5-20 \text { repetitions holding contraction } \\
\text { for } 15-20 \text { seconds; } 30 \text { seconds rest between sets and } \\
2 \text { minutes rest between exercises }\end{array}$ & $\begin{array}{l}\text { FR } d=I .49 \\
\text { Timed Up and Go (TUG) } d=0.49 \\
\text { I0-Meter Walk } d=0.85\end{array}$ \\
\hline Idland et $\mathrm{a}^{3 \mid}$ & $\begin{array}{l}\mathrm{F} \\
91.3 \pm 1.4\end{array}$ & $\begin{array}{l}\text { I-hour session, } 2 \text { days/week for } 12 \text { weeks } \\
\text { I0-minute aerobic warm-up. Four progressive compound } \\
\text { exercises for BLE and back muscles with } 2-3 \text { sets of } 8-12 \\
\text { repetitions. Load was increased when participant could } \\
\text { perform I-2 repetitions above desired amount }\end{array}$ & $\begin{array}{l}\text { TUG } d=I .45 \\
\text { Normal Gait Speed } d=1.98 \\
\text { 30-Second Chair Stands } d=2.42\end{array}$ \\
\hline Kahle and Tevald ${ }^{26}$ & $\begin{array}{l}M \& F \\
76.5 \pm 6.9\end{array}$ & $\begin{array}{l}20-35 \text {-minute session, } 3 \text { days/week for } 6 \text { weeks. Isometric } \\
\text { and dynamic contractions of the core muscles focusing } \\
\text { on slow and controlled motions with } 5-25 \text { seconds per } \\
\text { repetition; I-2-minute rest between sets. Intensity was } \\
\text { progressed every } 2 \text { weeks }\end{array}$ & $\begin{array}{l}\text { FR } d=1.3 \\
\text { Star Excursion Balance Test } \\
d=1.9 \\
\text { Curl Up } d=4.4\end{array}$ \\
\hline Kobayashi et a ${ }^{27}$ & $\begin{array}{l}M \& F \\
67.5 \pm 5.23\end{array}$ & $\begin{array}{l}3 \text { days/week for } 8 \text { weeks.* Full body beginning movement } \\
\text { load training: movement corresponds to an axial rotation } \\
\text { about the involved limb segments to facilitate nonplanar } \\
\text { motion. Resistance varies through ROM. Participants } \\
\text { performed 5-7 sets of I } 5 \text { repetitions. Exercises were } \\
\text { performed at } 30 \% \text { I RM and the intensity remained } \\
\text { unchanged }\end{array}$ & $\begin{array}{l}\text { Timed Chair Rise } d=0.97 \\
\text { Timed Eyes Closed SLB } d=0.8 \mathrm{I} \\
\text { Timed Stair Ascent } d=0.50 \\
\text { Timed Stair Descent } d=0.77\end{array}$ \\
\hline Lustosa et $\mathrm{a}^{28}$ & $\begin{array}{l}F \\
72.0 \pm 4.0\end{array}$ & $\begin{array}{l}\text { I-hour session, } 3 \text { days/week for } 10 \text { weeks } \\
\text { Exercises targeted large BLE muscle groups with three } \\
\text { sets of eight repetitions using } 70 \%-75 \% \text { I RM }\end{array}$ & $\begin{array}{l}\text { TUG } d=0.32 \\
\text { I0-Meter Walk Test } d=0.70\end{array}$ \\
\hline Nicholson et a ${ }^{29}$ & $\begin{array}{l}\text { M\&F } \\
66.0 \pm 4.0\end{array}$ & $\begin{array}{l}\text { I-hour session, } 2 \text { days/week for } 26 \text { weeks } \\
\text { BodyPump: full body, prechoreographed group } \\
\text { exercise class utilizing low weight and very high reps } \\
\text { (around } 70-100 \text { ) per body part. Intensity was set at } \\
\text { 10\%-30\% I RM }\end{array}$ & $\begin{array}{l}\text { TUG } d=0.8 \text { I } \\
\text { Normal Gait Speed } d=0.95 \\
\text { Fast Gait Speed } d=0.63 \\
\text { Chair Stand Test } d=0.26\end{array}$ \\
\hline Pamukoff et al ${ }^{32}$ & $\begin{array}{l}M \& F \\
70.8 \pm 4.4\end{array}$ & $\begin{array}{l}\text { I-hour session, } 3 \text { days/week for } 6 \text { weeks } \\
\text { Exercises targeted large muscle groups of the BLE. } \\
\text { Performed at } 50 \% \text { I RM with three sets of } 8-10 \\
\text { repetitions; } 2-3 \text { minutes rest between sets }\end{array}$ & $\begin{array}{l}\text { Max Forward Lean } d=0.82 \\
\text { Max Lateral Lean } d=0.88\end{array}$ \\
\hline Persch et $\mathrm{al}^{30}$ & $\begin{array}{l}F \\
61.1 \pm 4.3\end{array}$ & $\begin{array}{l}3 \text { days/week for } 12 \text { weeks.* BLE strengthening exercises } \\
\text { performed on pulley machines. Two sets of } 10-12 \\
\text { repetitions with } 2 \text {-minute rest in-between sets. Intensity } \\
\text { was increased when the participant completed more than } \\
12 \text { reps. Verbal encouragement was given at the end of } \\
\text { each exercise series }\end{array}$ & $\begin{array}{l}\text { Gait Speed } d=2.41 \\
\text { Stride Length } d=3.09 \\
\text { Cadence } d=4.09 \\
\text { Toe Clearance } d=0.33\end{array}$ \\
\hline Yamada et $\mathrm{a}^{33}$ & $\begin{array}{l}\text { M\&F } \\
75.8 \pm 8.0\end{array}$ & $\begin{array}{l}\text { I-hour session, } 2 \text { days/week for } 50 \text { weeks. I5-minute } \\
\text { aerobic warm-up and I0-minute stretching cool-down at } \\
\text { end. Exercises on resistance-training machines targeted } \\
\text { BLE and trunk muscles. Participants performed three sets } \\
\text { of } 10 \text { repetitions on each machine }\end{array}$ & $\begin{array}{l}\text { TUG Frail } d=0.37 \\
\text { SLB Frail } d=0.22 \\
\text { FR Frail } d=0.47 \\
\text { Five Chair Stand Frail } d=0.24 \\
\text { Falls Efficacy Scale Frail } d=0.60\end{array}$ \\
\hline
\end{tabular}

Notes: *Duration of exercise session not specified. $d$ between-groups effect size, calculated as Cohen's $d$.

Abbreviations: FR, Functional Reach test; SD, standard deviation; SLB, Single Leg Balance test; TUG, Timed Up and Go test; M, male; F, female; BLE, bilateral lower extremity; ROM, range of motion, RT, resistance training. 
sarcopenia. Despite commonly accepted recommendations, ${ }^{9}$ there has been no definitive gold standard prescription for resistance training exercise for mobility outcomes. This is due in-part, to the heterogeneity of task outcomes, participant demographics, and training regimens (dose, mode, and progression). Nowithstanding the challenges associated with diverse approaches to empirical research in resistance training, one essential conclusion can be drawn from these studies: doing something is better than doing nothing. Clinicians tend to acknowledge this principle ${ }^{40}$ but research has become so prescriptive that it often overlooks the simplicity of the recommendation. However, Smith et al underscored the importance of continuous moderate amounts of activity in older adults by longitudinally examining exercise in two different groups (mean age of 72.5 years) over a 5 -year period. ${ }^{41}$ The first group performed resistance training throughout the entire 5 years (Trained), while the other group stopped after 2 years (Detrained). Both groups trained at $80 \%$ of their own 1 RM. The two groups significantly improved muscle strength at the end of two years. However, at the 5 year follow-up the Detrained group lost strength compared to the two-year checkpoint. Interestingly however, the overall strength in this Detrained group was still 15.6\% higher compared to baseline. Thus, doing something over the two year period was clearly better than doing nothing. Clinicians should confidently recommend that staying physically active can help mitigate the loss in skeletal muscle mass associated with aging.

\section{Summary}

Resistance training offers numerous benefits beyond improvements in muscle strength alone for older individuals. Several reports have demonstrated improvements in balance, functional mobility, stability limits, and fall prevention. Resistance training can attenuate age-related changes in muscle function and improve activities of daily living such as walking endurance, gait speed, and stair climbing. Our research demonstrates that a significant increase in functional performance can be achieved even at an elderly age ( $>90$ years old).

Notwithstanding the numerous well-known advantages of resistance training, older adults often have difficulty obtaining recommended daily doses of physical activity. In these instances, clinicians should focus on what patients can do instead of what they cannot do. Encouraging patients to be active is paramount; advocating for increased activity levels along a spectrum of mobility, with "no activity" on one end, and "recommended daily amounts" on the other. As clinicians encourage patients to move along that spectrum toward prescribed levels, patients will gain confidence in their mobility and increase intrinsic motivation toward a progressive modicum of greater activity.

\section{Acknowledgments}

The authors would like to thank Hillary Hummel-Kerbs for her assistance with compiling and organizing data into the table in this report.

Research reported in this publication was supported by the National Center for Advancing Translational Sciences of the National Institutes of Health under award Number KL2TR001103. The content is solely the responsibility of the authors and does not necessarily represent the official views of the NIH.

\section{Disclosure}

The authors report no conflicts of interest in this work.

\section{References}

1. Moore I. Geriatrics is a wide open field. Available from: http://www.americangeriatrics.org/health_care_professionals/profiles_in_geriatrics/ irene_moore/. Accessed July 29, 2016.

2. Centers for Disease Control and Prevention. General Information about the Older Adult Population. 2015. Available from: http://www.cdc.gov/ aging/emergency/general.htm. Accessed May 11, 2017.

3. Walston J, Hadley EC, Ferrucci L, et al. Research agenda for frailty in older adults: toward a better understanding of physiology and etiology: summary from the American Geriatrics Society/National Institute on Aging Research Conference on Frailty in Older Adults. J Am Geriatr Soc. 2006;54(6):991-1001.

4. Newman AB, Haggerty CL, Goodpaster B, et al; Health Aging and Body Composition Research Group. Strength and muscle quality in a well-functioning cohort of older adults: the health, aging and body composition study. J Am Geriatr Soc. 2003;51(3):323-330.

5. Doherty TJ. Invited review: aging and sarcopenia. J Appl Physiol. 2003; 95(4):1717-1727.

6. Rosenberg IH. Sarcopenia: origins and clinical relevance. J Nutr. 1997;127(5 Suppl):990S-991S.

7. Rosenberg IH. Summary comments: epidemiological and methodological problems in determining nutritional status of older persons. Am J Clin Nutr. 1989;50:1231-1233.

8. Janssen I, Heymsfield SB, Ross R. Low relative skeletal muscle mass (sarcopenia) in older persons is associated with functional impairment and physical disability. Journal of the American Geriatrics Society. 2002; 50(5):889-896.

9. American College of Sports Medicine, Chodzko-Zajko WJ, Proctor DN, et al. American College of Sports Medicine position stand. Exercise and physical activity for older adults. Med Sci Sports Exerc. 2009;41(7):1510-1530.

10. Reeves ND, Narici MV, Maganaris CN. Effect of resistance training on skeletal muscle-specific force in elderly humans. $J$ Appl Physiol. 2004;96(3):885-892.

11. Vincent KR, Braith RW, Feldman RA, et al. Resistance exercise and physical performance in adults aged 60 to 83. J Am Geriatr Soc. 2002; 50(6):1100-1107.

12. Latham N, Anderson C, Bennett D, Stretton C. Progressive resistance strength training for physical disability in older people. Cochrane Database Syst Rev. 2003;(2):CD002759.

13. Higgins J, Green S, Scholten R. Chapter 3: maintaining reviews: updates, amendments and feedback. Cochrane handbook for systematic reviews of interventions, version 5.1.0. 2011; Available from: http:// handbook.cochrane.org. Accessed December 3, 2016. 
14. Peterson MD, Rhea MR, Sen A, Gordon PM. Resistance exercise for muscular strength in older adults: a meta-analysis. Ageing Res Rev. 2010;9(3):226-237.

15. Baker MK, Atlantis E, Fiatarone Singh MA. Multi-modal exercise programs for older adults. Age Ageing. 2007;36(4):375-381.

16. Moher D, Liberati A, Tetzlaff J, Altman DG. Preferred reporting items for systematic reviews and meta-analyses: the PRISMA statement. $J$ Clin Epidemiol. 2009;62(10):1006-1012.

17. AACPDM Methodology to Develop Systematic Reviews of Treatment Interventions. 2008; Available from: http://www.aacpdm.org/UserFiles/ file/systematic-review-methodology.pdf. Accessed December 7, 2016.

18. Wiart L, Kolaski K, Butler C, et al. Interrater reliability and convergent validity of the American Academy for Cerebral Palsy and Developmental Medicine methodology for conducting systematic reviews. Dev Med Child Neurol. 2012;54(7):606-611.

19. American College of Sports Medicine. American College of Sports Medicine position stand. Progression models in resistance training for healthy adults. Med Sci Sports Exerc. 2009;41(3):687-708.

20. Stucki G. International classification of functioning, disability, and health (ICF): a promising framework and classification for rehabilitation medicine. Am J Phys Med Rehabil. 2005;84(10):733-740.

21. Garner P, Hopewell S, Chandler J, et al. When and how to update systematic reviews: consensus and checklist. Bmj. 2016;354:i3507.

22. Liu CJ, Latham NK. Progressive resistance strength training for improving physical function in older adults. Cochrane Database Syst Rev. 2009;(3):CD002759.

23. Gonzalez AM, Mangine GT, Fragala MS, et al. Resistance training improves single leg stance performance in older adults. Aging Clin Exp Res. 2014;26(1):89-92.

24. Granacher U, Gruber M, Gollhofer A. Resistance training and neuromuscular performance in seniors. Int J Sports Med. 2009;30(9):652-657.

25. Granacher U, Lacroix A, Muehlbauer T, Roettger K, Gollhofer A. Effects of core instability strength training on trunk muscle strength, spinal mobility, dynamic balance and functional mobility in older adults. Gerontology. 2013;59(2):105-113.

26. Kahle N, Tevald MA. Core muscle strengthening's improvement of balance performance in community-dwelling older adults: a pilot study. $J$ Aging Phys Act. 2014;22(1):65-73.

27. Kobayashi H, Koyama Y, Enoka RM, Suzuki S. A unique form of lightload training improves steadiness and performance on some functional tasks in older adults. Scand J Med Sci Sports. 2014;24(1):98-110.
28. Lustosa LP, Silva JP, Coelho FM, Pereira DS, Parentoni AN, Pereira LS Impact of resistance exercise program on functional capacity and muscular strength of knee extensor in pre-frail community-dwelling older women: a randomized crossover trial. Rev Bras Fisioter. 2011;15(4):318-324.

29. Nicholson VP, McKean MR, Burkett BJ. Low-load high-repetition resistance training improves strength and gait speed in middle-aged and older adults. J Sci Med Sport. 2015;18(5):596-600.

30. Persch LN, Ugrinowitsch C, Pereira G, Rodacki AL. Strength training improves fall-related gait kinematics in the elderly: a randomized controlled trial. Clin Biomech (Bristol, Avon). 2009;24(10):819-825.

31. Idland G, Sylliaas H, Mengshoel AM, Pettersen R, Bergland A. Progressive resistance training for community-dwelling women aged 90 or older; a single-subject experimental design. Disabil Rehabil. 2014;36(15):1240-1248.

32. Pamukoff DN, Haakonssen EC, Zaccaria JA, Madigan ML, Miller ME, Marsh AP. The effects of strength and power training on single-step balance recovery in older adults: a preliminary study. Clin Interv Aging. 2014;9:697-704

33. Yamada M, Arai H, Uemura K, et al. Effect of resistance training on physical performance and fear of falling in elderly with different levels of physical well-being. Age Ageing. 2011;40(5):637-641.

34. Duncan PW, Studenski S, Chandler J, Prescott B. Functional reach: predictive validity in a sample of elderly male veterans. J Gerontol. 1992; 47(3):M93-M98.

35. Duncan PW, Weiner DK, Chandler J, Studenski S. Functional reach: a new clinical measure of balance. J Gerontol. 1990;45(6):M192-M197.

36. Shumway-Cook A, Brauer S, Woollacott M. Predicting the probability for falls in community-dwelling older adults using the timed up \& go test. Phys Ther. 2000;80(9):896-903.

37. Quittan M. Aspects of physical medicine and rehabilitation in the treatment of deconditioned patients in the acute care setting: the role of skeletal muscle. Wien Med Wochenschr. 2016;166(1-2):28-38.

38. Larsson L. Histochemical characteristics of human skeletal muscle during aging. Acta Physiol Scand. 1983;117(3):469-471.

39. Ferguson B. ACSM's guidelines for exercise testing and prescription 9th ed. 2014. J Can Chiropr Assoc. 2014;58(3):328.

40. Hupin D, Roche F, Edouard P. Physical activity and successful aging: even a little is good. JAMA Intern Med. 2015;175(11):1862-1863.

41. Smith K, Winegard K, Hicks AL, McCartney N. Two years of resistance training in older men and women: the effects of three years of detraining on the retention of dynamic strength. Can J Appl Physiol. 2003;28(3): $462-474$.
Clinical Interventions in Aging

\section{Publish your work in this journal}

Clinical Interventions in Aging is an international, peer-reviewed journal focusing on evidence-based reports on the value or lack thereof of treatments intended to prevent or delay the onset of maladaptive correlates of aging in human beings. This journal is indexed on PubMed Central, MedLine,

\section{Dovepress}

CAS, Scopus and the Elsevier Bibliographic databases. The manuscript management system is completely online and includes a very quick and fair peer-review system, which is all easy to use. Visit http://www.dovepress. com/testimonials.php to read real quotes from published authors. 